\title{
Nanohardness of Electron Beam Irradiated HDPE
}

\author{
David Manas ${ }^{1, a}$, Martin Ovsik ${ }^{1, b}$, Miroslav Manas ${ }^{1, c}$, Michal Stanek ${ }^{1, d}$, Karel \\ Kocman $^{1, e}$, Martin Bednarik ${ }^{1, f}$, Vojtech Senkerik ${ }^{1, g}$ \\ ${ }^{1}$ Tomas Bata University in Zlin, TGM 5555, 76001 Zlin, Czech Republic \\ admanas@ft.utb.cz, bovsik@ft.utb.cz, 'cmanas@ft.utb.cz, dstanek@ft.utb.cz, ${ }^{\mathrm{e}}$ kocman@ft.utb.cz, \\ tbednarik@ft.utb.cz, ${ }^{9} v s e n k e r i k @ f t . u t b . c z$
}

Keywords: nanohardness, High-density polyethylene, irradiation cross - linking, DSI - Depth Sensing Indentation, surface layer.

\begin{abstract}
Micromechanical changes in the surface layer of High-density polyethylene HDPE modified by beta radiation were measured by instrumented test of nanohardness. The specimens were prepared by injection technology and subjected to radiation doses of $0,132,165,198 \mathrm{kGy}$. Measurements of nanohardness showed considerable changes of behavior of surface layer in middle as well as high radiation doses with higher values of indentation hardness and stiffness.
\end{abstract}

Introduction. Polymers belong to constructive materials which find use at the most industry branches. Many investigations have been reported on irradiation of polymers and its effects on chemical structure and its physical Properties The irradiation of polymers results in crosslinking, main-chain scission, and evolution of hydrogen. These reactions are related to the chemical and physical state of the polymer and the nature of irradiation. The industrial applications of crosslinking by irradiation with fast electrons has been used extensively for the production of heat shrinkable polyethylene films and tubes. Also, crosslinked polyethylene has been used in hot water piping installation, wire and cable industries. Today, more than 800 electron beam facilities are in operation in the treatment of polymer products in the world. The electron-beam energy of these machines normally is less than $5 \mathrm{MeV}$. Now, the higher performance electron beam machines of 10 $\mathrm{MeV}$ offer new application possibilities [1-4].

Since crosslinked HDPE has a thermally stable form, it may be utilized as a thermal energy storage material in direct contact with the heat transferred, ethylene glycol. This thermally stable form of HDPE does not require separate packaging which increases the cost of the thermal energy storage system. Thus HDPE has been recommended as an economical thermal energy storage material with its large heat of fusion, relatively low cost and congruent melting behavior [2].

Degradation is the major problem in the development of HDPE as a thermal energy storage material. Especially thermal oxidative degradation of HDPE produces low molecular weight products and oxygenated products, which have effects on melting point, heat of fusion and crystallinity. As thermal oxidative degradation proceeds, the amount of the degraded products becomes larger and the crystallinity of HDPE decreases, and hence the performance of the thermal energy storage system declines. In order to use HDPE as a thermal energy storage material, it should not be degraded during the period of application [4-8].

\section{Experimental}

For this experiment High Density Polyethylene HDPE DOW - HDPE 25055E, DOW - Chemical company, USA (unfilled, HDPE) was used. The prepared specimens were irradiated with doses of 0, 33, 66 and 99 kGy at BGS Beta-Gamma Service GmbH \& Co. KG, Germany. 
The samples were made using the injection molding technology on the injection molding machine Arburg Allrounder 420C. Processing temperature $220-280{ }^{\circ} \mathrm{C}$, mold temperature $70{ }^{\circ} \mathrm{C}$, injection pressure $65 \mathrm{MPa}$, injection rate $45 \mathrm{~mm} / \mathrm{s}$.

Instrumented nanohardness tests were done using a Nanoindentation Tester (NHT2) - Opx/Cpx , CSM Instruments (Switzerland) according to the CSN EN ISO 14577-1. Load and unload speed was $20 \mathrm{mN} / \mathrm{min}$. After a holding time of $90 \mathrm{~s}$ at maximum load $10 \mathrm{mN}$ the specimens were unloaded. The specimens were glued on metallic sample holders. Fifteen specimens were tested and average values are reported.

The indentation hardness $\mathrm{H}_{\mathrm{IT}}$ was calculated as maximum load to the projected area of the hardness impression according to [3-4]:

$$
H_{I T}=\frac{F_{\max }}{A_{p}}
$$

The indentation modulus is calculated from the Plane Strain modulus using an estimated sample Poisson's ratio:

$$
E_{I T}=E^{*} \cdot\left(1-v_{s}^{2}\right)
$$

Determination of indentation creep $\mathrm{C}_{\mathrm{IT}}$ (as can be seen at Fig. 1):

$$
C_{I T}=\frac{h_{2}-h_{1}}{h_{1}} \cdot 100
$$

Where $h_{1}$ is the indentation depth at time $t_{1}$ of reaching the test force (which is kept constant), $h_{2}$ is the indentation depth at time $t_{2}$ of holding the constant test force [5-6].

Elastic part of the indentation work $\eta_{\mathrm{IT}}$ (as can be seen at Fig. 2):

$$
\eta_{I T}=\frac{W_{\text {elast }}}{W_{\text {total }}} \cdot 100
$$

with

$$
W_{\text {tota }}=W_{\text {elast }}+W_{\text {plast }}
$$

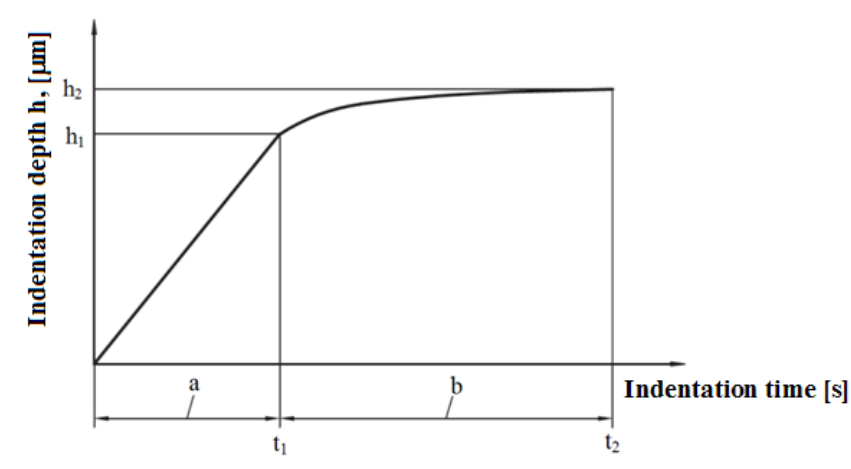

Fig. 1 Expression of indentation creep

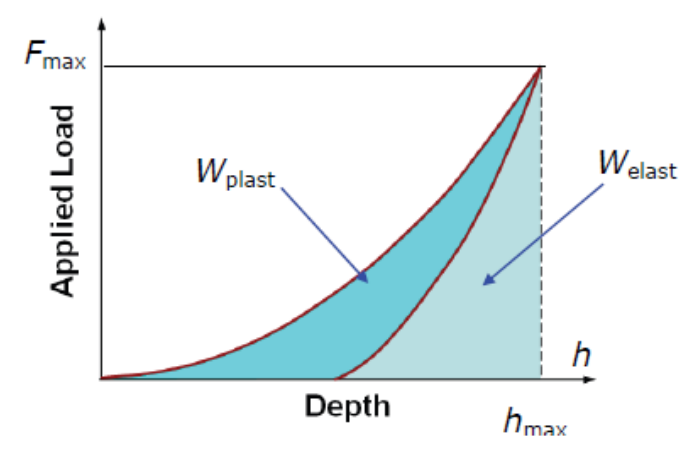

Fig. 2 Indentation work

\section{Results and discussion}

Radiation crosslinking creates changes in the HDPE structure by creating 3D net. Beta radiation gradually penetrates more deeply into the HDPE structure through the surface layer. The surface layer undergoes changes which have a considerable influence on the micromechanical properties of HDPE.

Measurements of nanohardnes of HDPE modified by beta radiation showed that the highest values of indentation hardness were found for HDPE modified by the radiation dose of $165 \mathrm{kGy}$. The smallest value of indentation hardness was found for non-irradiated HDPE. The increase of indentation hardness value for HDPE irradiated by the dose of $165 \mathrm{kGy}$ was by $9 \%$ (Fig. 3) in comparison with the non-irradiated HDPE . 
Radiation, which penetrated through specimens gradually formed cross-linking (3D net), first in the surface layer and then in the total volume, which resulted in considerable changes in specimen behavior.

In the case of elastic modulus the highest value was found for HDPE irradiated by the radiation dose of $165 \mathrm{kGy}$. Non-irradiated HDPE obtained the second highest value of elastic modulus. The smallest value of elastic modulus was found for HDPE irradiated by the radiation dose of $198 \mathrm{kGy}$ (Fig. 4).

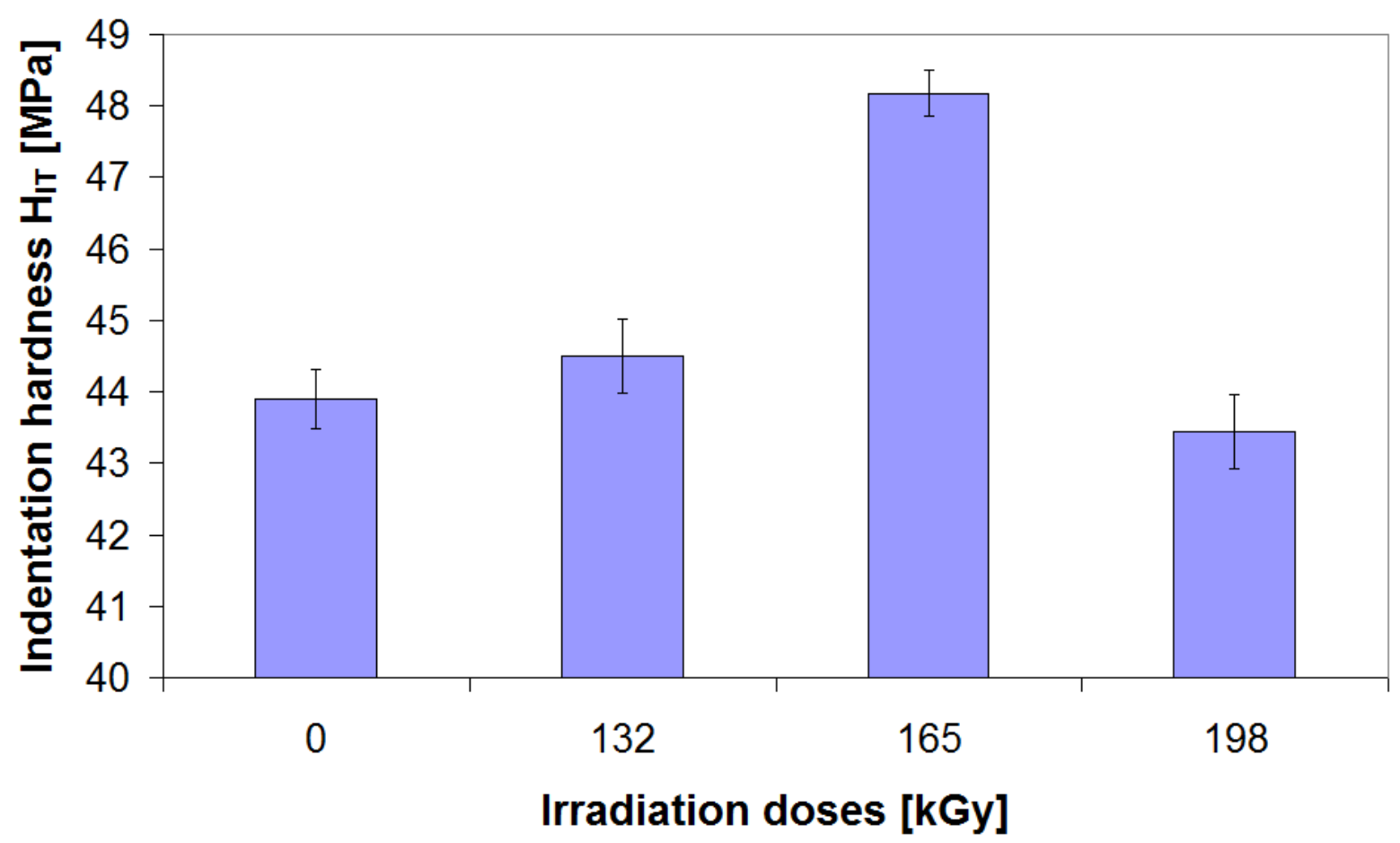

Fig. 3 Hardness $\mathrm{H}_{\mathrm{IT}}$ vs. irradiation doses of HDPE

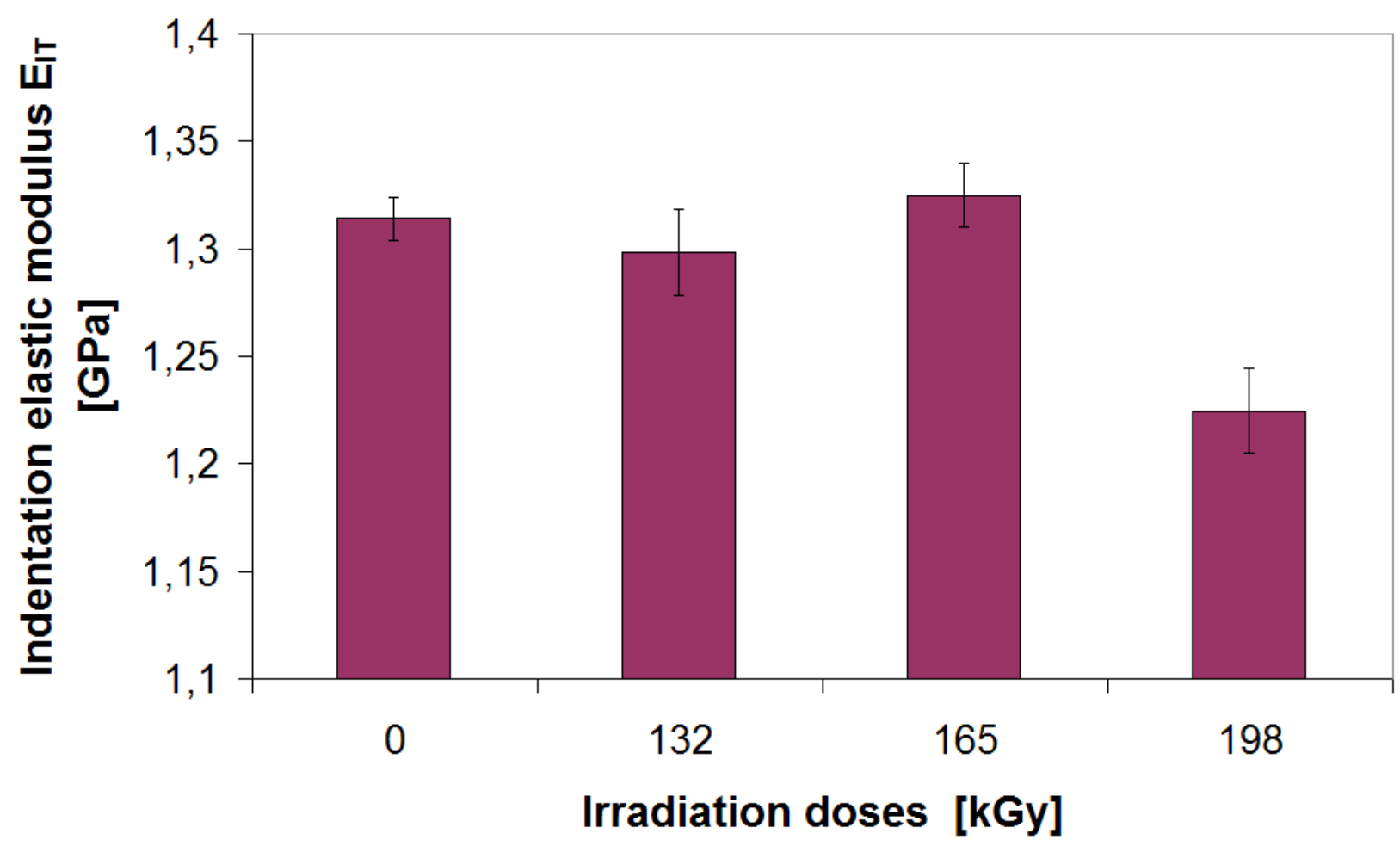

Fig. 4 Indentation modulus $\mathrm{E}_{\mathrm{IT}}$ vs. irradiation doses of HDPE 
Interesting results were found for elastic and plastic deformation work. The highest value of plastic work was measured for non-irradiated HDPE while the highest value of elastic deformation work was found at the radiation dose of $198 \mathrm{kGy}$. The lowest value of plastic work was found at radiation dose of $198 \mathrm{kGy}$ (Fig. 5). Also, the value of elastic part of indentation work $\eta_{\text {IT }}$ which provides information about the relaxation of the indent created in HDPE was the smallest at radiation dose of $0 \mathrm{kGy}$.

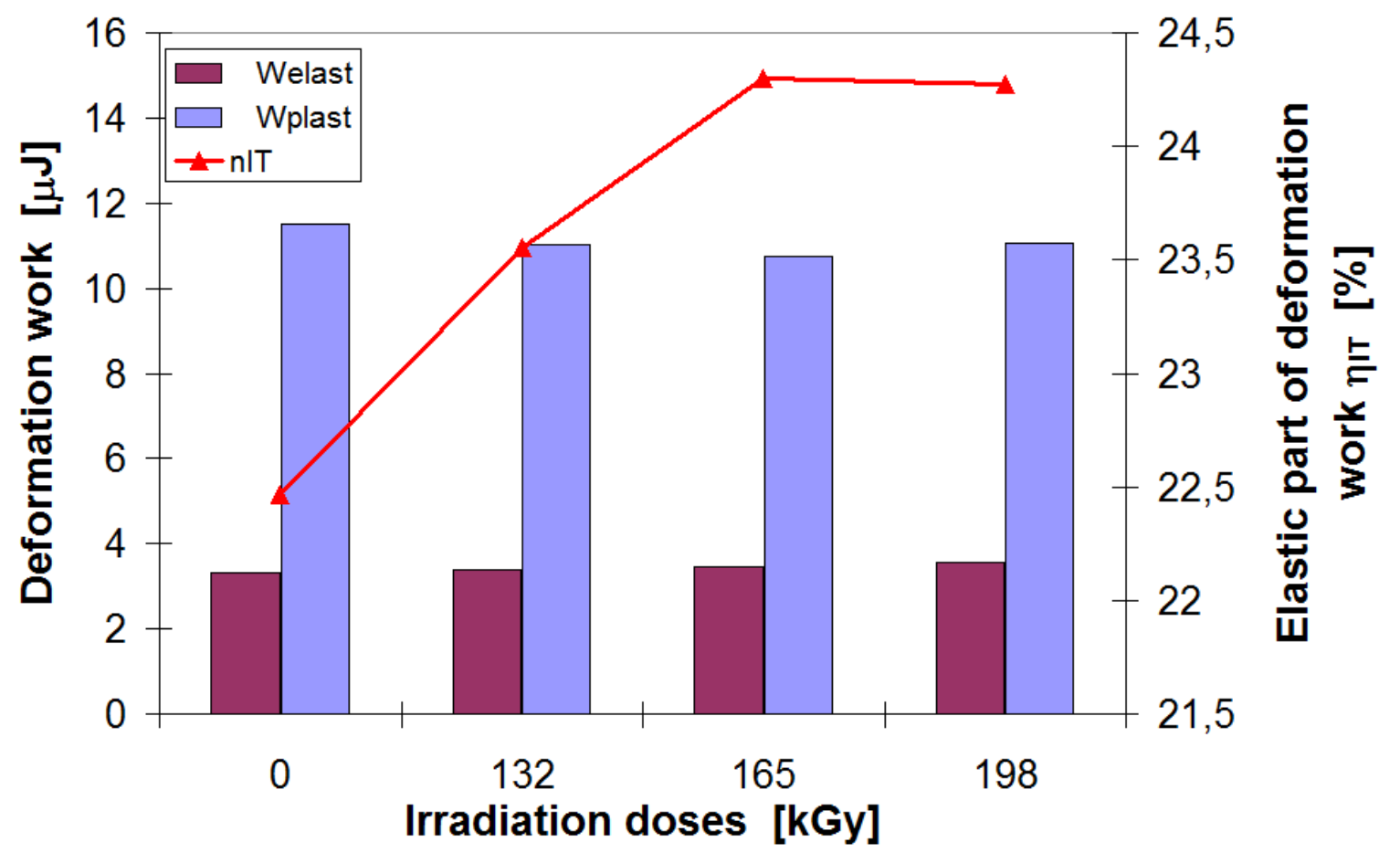

Fig. 5 Deformation work vs. irradiation dose of HDPE

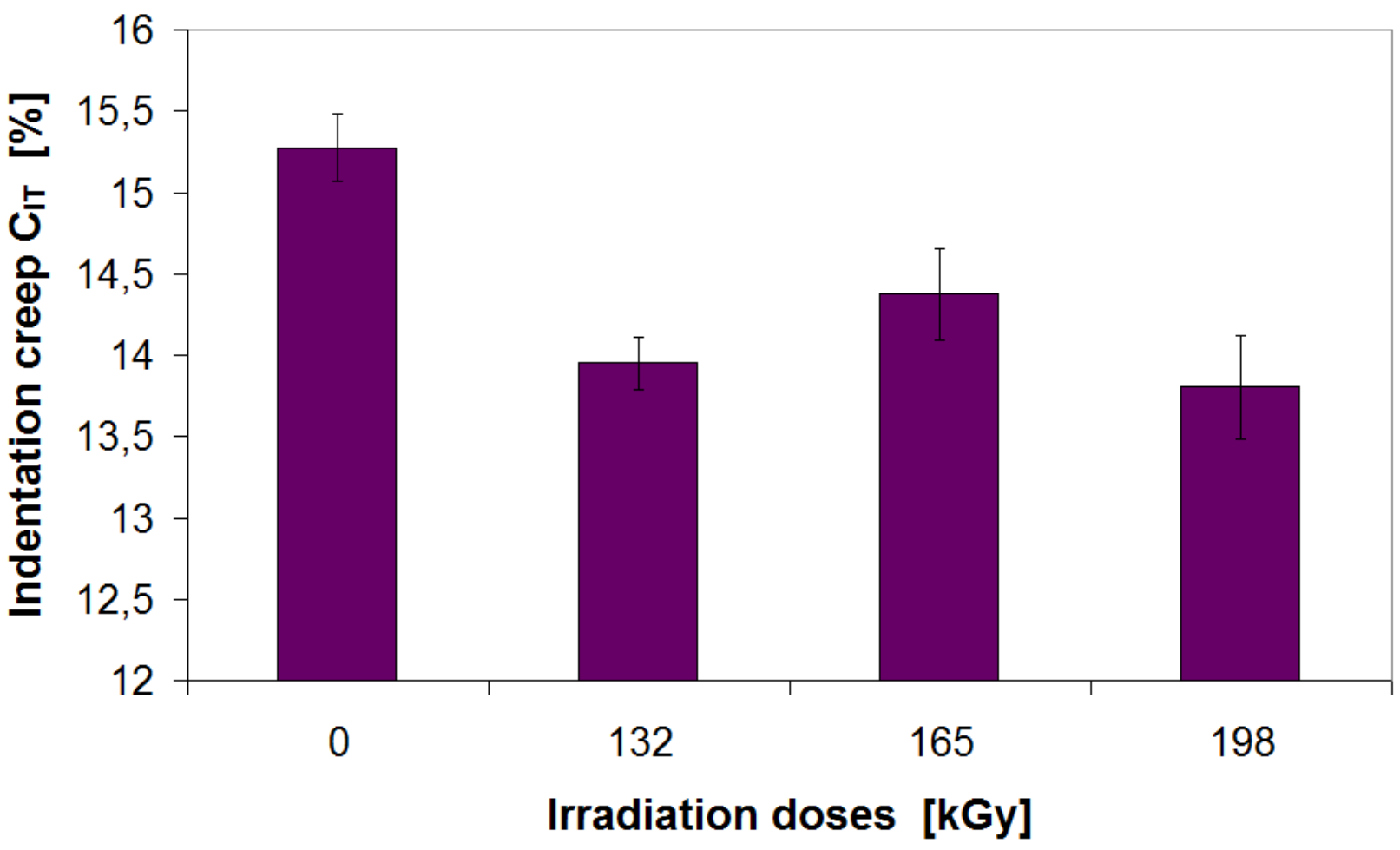

Fig. 6 Indentation creep $C_{\mathrm{IT}}$ vs. irradiation dose of HDPE 
Very important values were found for indentation creep. The lowest value of creep was measured at radiation dose of $198 \mathrm{kGy}$. The highest creep value measured for non-irradiated HDPE. Decrease in creep values was $10 \%$ for irradiated HDPE compared to the non-irradiated one as is seen at Fig. 6.

\section{Conclusion}

The experimental study deals with the effect of modification of the surface layer by irradiation cross-linking on the properties of the surface layer of HDPE. High-density polyethylene was modified by beta irradiation at doses of 0,132, 165, $199 \mathrm{kGy}$. The greatest changes of micromechanical properties were found at the radiation dose of $165 \mathrm{kGy}$, for indentation hardness, which increased by $9 \%$ compared to the non-irradiated HDPE.

Improvement of mechanical properties in micro and macro scale of radiated HDPE has a great significance also for industry. The modified HDPE shifts to the group of materials which have considerably better properties. Its micromechanical properties make HDPE ideal for a wide application in the areas where higher resistance to wear, creep are required. Commonly manufactured HDPE can hardly fulfill these criteria.

\section{Acknowledgment}

This paper is supported by the internal grant of TBU in Zlin No. IGA/FT/2014/016 funded from the resources of specific university research and by the European Regional Development Fund under the project CEBIA-Tech No. CZ.1.05/2.1.00/03.0089 and Technology Agency of the Czech Republic as a part of the project called TA03010724 AV and EV LED luminaire with a higher degree of protection.

\section{References}

[1] M. Ovsik, D. Manas, M. Manas, M. Stanek, M. Hribova, K. Kocman, D. Samek, Irradiated Polypropylene Studied by Microhardness and WAXS, Chemicke listy, 106 (2012), 507-510.

[2] G. Zamfirova, V. Gaydarov, T. Zaharescu, L. G. Silva, Microindentation study of Electron Beam Irradiated Polyamide Samples, Chemicke Listy, 104 (2010), 283-286.

[3] D. Manas, M. Hribova, M. Manas, M. Ovsik, Stanek, Effect of Beta Irradiation on Morphology and Microhardness of Polypropylene Thin Layers, Thin Solid Films 530, (2013), 49-52.

[4] W.C. Oliver, G.M. Pharr, Measurement of Hardness and Elastic Modulus by Instrumented Indentation, Journal of Materials Research 19 (1), (2004), 1564 - 1583.

[5] A. Bolshakov and G. M. Pharr, Influences of pile-up on the measurement of mechanical properties by load and depth sensing indentation. J. Mater. Res. 13. (1998) p. 1049-1058.

[6] A. Pusz, K. Michalik, Creep damage mechanisms in gas pipes made of high density polyethylene,2009 Archives of Materials Science and Engineering 36 (2) , pp. 89-95

[7] W. C. Oliver, G.M. Pharr. J Mater Res 7 (6), 1992 pp. 1564-1583.

[8] M. Manas, D. Manas, M. Stanek, S. Sanda, V. Pata,Improvement of Mechanical Properties of the TPE by Irradiation“, 2011, Chemicke listy, Volume 105, Issue 17, pp. S828-S829 